\title{
THE ACCURACY OF IMPLANT POSITIONING USING BONE SUPPORTED VERSUS MUCOSA SUPPORTED SURGICAL GUIDE TEMPLATES FOR IMPLANT ASSISTED LOWER COMPLETE OVERDENTURE
}

\author{
Faten A.S. Abutaleb*, Hesham S. Borg ${ }^{* *}$, Mahmoud E.Khalifa***, \\ Rafic R. Bader ${ }^{* * * *}$ and Mohamed K. Allam ****
}

\begin{abstract}
Purpose: Evaluation of the accuracy of implants position using two different types of computer-aided design/computer-aided manufacturing (CAD/CAM) surgical guides, including bone supported and mucosa supported guided templates.

Materials and methods: Twelve completely edentulous patients were selected for this study and divided into two groups six each. all patients received a radiopaque radiographic template. A cone beam computed tomography was taken to simulate the position of the two implants, virtual implants were drawn in its place, fabrication of surgical guide template using rapid prototyping technique to match the position of virtual implant according to patient' group. Group I bone supported surgical guide(BSG) and group II mucosa supported surgical guide (MSG). The implants were installed for each patient using surgical guide templates according to the group. The positions and angulations of the placed implants in comparison to those of the planned ones were determined using special software that matched pre- and postoperative computed tomography (CT) images, and deviations were calculated and compared between the two guide templates using a software program to detect any difference in linear and angular deviation. Data were collected; tabulated and analyzed using student $\mathrm{T}$ test.
\end{abstract}

Results : There was no significant difference of both linear and angular measurements between virtual and the surgically placed implants for both groups. Also there was insignificant difference in accuracy between group I (bone supported) and group II (mucosa supported).

Conclusions: Using template-guided surgery enables the clinician to optimize implant position, angle, diameter and length by dictating the drilling position and angulation. Cone beam CT has accurate measurements in distances between two implants as clinical measurements. The bone supported surgical guide as well as the mucosa supported surgical guide has the same accuracy in implant positioning.

KEYWORDS: Dental implant, cone beam computed tomography, computer-aided design/ computer-aided manufacture, bone-supported surgical guide, mucosa-supported surgical guide.

\footnotetext{
* Assistant Prof of Removable Prosthodontics, Prosthodontic Department, Faculty of Dentistry, Tanta University ** Lecturer of Removable Prosthodontics, Prosthodontic Department, Faculty of Dentistry, October 6 University. *** Assistant Prof. Oral and Maxillofacial Surgery, Faculty of Dentistry,Tanta university, Egypt **** Lecturer of Oral and Maxillofacial Surgery, Faculty of Dentistry,Tanta University, Egypt
} 


\section{INTRODUCTION}

Implant assisted prosthesis assures good aesthetics, function and more importantly hygiene maintenance enabling long time success. Accuracy in treatment planning and implementation of planned treatment is vital for this success. Misaligned implants often complicate the clinical laboratory procedures employed for fabrication of superstructures. Due to improper load distribution, an overall increase in stress concentration on supporting structures may occur. This may compromise the maintenance of the bone implant interface. ${ }^{[1]}$ Conventional dental radiographs (panoramic and periapical) and conventionally fabricated surgical guides are usually used for implant placement ${ }^{[2-4]}$

According to the g Glossary of prosthodontics terms, the surgical template guide is used to assist in proper surgical placement and angulation of dental implants and predetermining the appropriate osteotomy path for the clinician and significantly helps the surgical procedure ${ }^{[5]}$. The conventionally fabricated surgical guides did not provide information about the varying thicknesses of the mucosa, topography of the underlying bone, or anatomical structures, furthermore, they do not remain stable during surgery ${ }^{[6]}$.

There are three types of surgical guide depending on the method of support as tooth supported, bone supported and mucosa supported ${ }^{[7]}$. Toothsupported guides are used in partially edentulous cases and designed to rest on other teeth in the arch. Mucosa-supported guides are used primarily in fully edentulous cases and are designed to rest on the mucosa, while bone-supported guides can be used in partially or fully edentulous cases, but are used primarily in fully edentulous cases in which significant ridge atrophy is present and good seating of a mucosa supported guide is questionable. These guides require elevation of an extensive fullthickness flap to expose the bone in the planned implant sites and in the adjacent areas for full, stable seating of the guide over the bony ridge ${ }^{[8]}$.
Now days, computed tomography (CT) has been introduced for pre-surgical implant planning, the assessment of the accurate position and precise dimensions of the implant, ideal depth, and angulations, moreover, prosthetically directed implant placement using computer software can ensure predictable prosthetic outcomes. Computeraided design/computer-aided manufacturing (CAD/ CAM) stereolithographic (SLA) surgical guides offer a significant advantage to the surgeon by improving precision and minimizing complications such as mandibular nerve damage, sinus perforation, fenestrations, and dehiscence ${ }^{[9,10]}$.

With the advancement of rapid prototype medical modeling manufactured from $\mathrm{CBCT}$, the information from CBCT images could be transferred directly to the patient via a prefabricated surgical stent ${ }^{[11]}$.The use of software systems with CBCT imaging has become one of the primary tools used for dental presurgical implant treatment planning. Not only can one select for a particular implant size and length, but also alveolar ridge height and width as well as the proximity of adjacent anatomic structures can be determined. Areas of inadequate ridge height or width can be identified and then considered for ridge augmentation procedures ${ }^{[12]}$.

Different accuracy measurement techniques and terms have been introduced in the literature in the comparison of planned implant positions to actual inserted implants. Some use baseline criteria such as entry or apical point while others use 3D coordinates (eg, x-, y-, and z-axes), making it more challenging to conduct a unified comparison. ${ }^{[13]}$. Research has been made to measure which method of guide support is the most precise and findings conclude that mucosa and teeth supported guides offer the best support. However, more research will be needed in order to better assess the precision

There is a need to evaluate clinically the applications of the bone supported surgical guide and its effect on the treatment outcome in oral implantology compared to the mucosa supported surgical guide. 
The null hypothesis that there is no difference in accuracy between bone supported and mucosa supported surgical guide in precise implant installation.

\section{MATERIALS AND METHODS}

This randomized controlled study was conducted on twelve completely edentulous patients selected from outpatient clinic of prosthodontics department, Faculty of dentistry, Tanta University. The patients were selected with following criteria, age of the patients was ranging from 45-65 years old, good general health, sufficient bone volume in the interforaminal region of the mandible, class I relation according to angle's classification, absence of mucosal lesion, sufficient inter-arch spaces. Complete maxillary and mandibular denture were fabricated for every patient according to standardized conventional technique.

The mandibular denture was duplicated by the basic protocol for duplicating a denture to create a radiographic guide. 8-10 holes placed at occlusal surfaces and cingulum areas using a slow-speed hand piece and $1 \mathrm{~mm}$ round bur, holes was drilled into the guide approximately $1 \mathrm{~mm}$ deep. Guttapercha was warmed and packed into the holes until full, and excess gutta-percha material was scraped away (Fig1.A) .The radiographic template was scanned by cone beam computed tomography

\section{A}

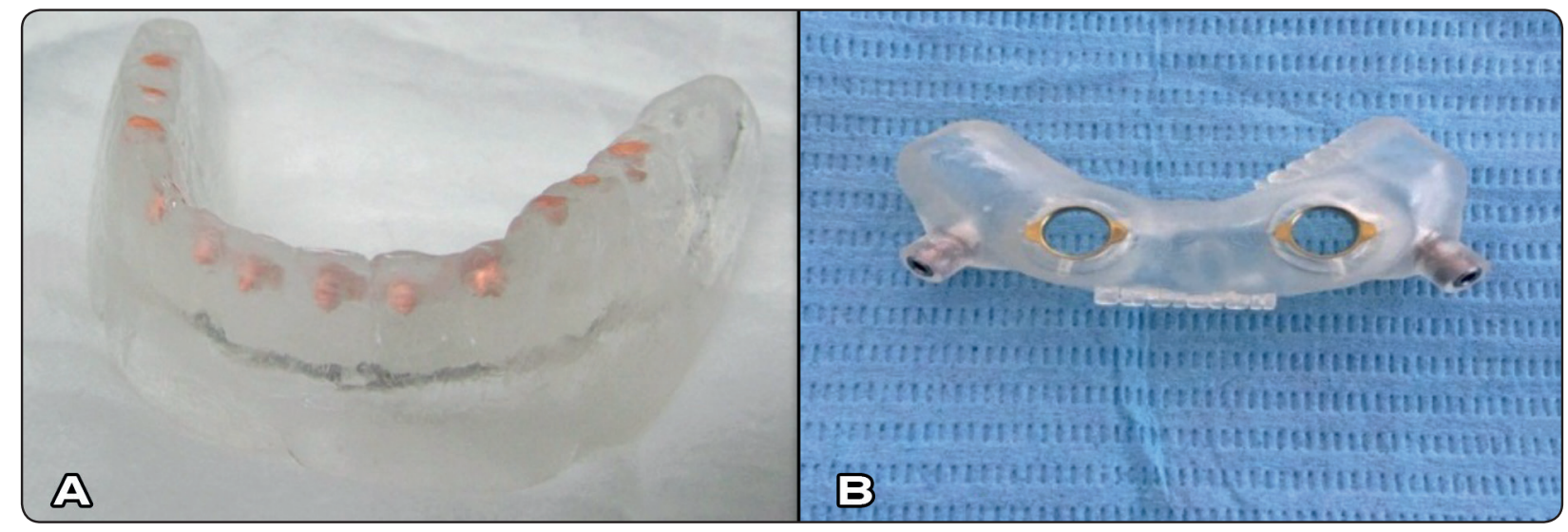

Fig. (1) (A) Radiographic template with guttapercha markers (B) The stereolithographic surgical guide after final printing.
(C.B.C.T.) at $10 \mathrm{~mA} .85 \mathrm{KV}$. All patients participated in this study were divided randomly into two groups placement.

The patients were asked to wear the radiographic template in the mandible and the upper denture and radiographed by cone beam computed tomography (CBCT) : (dual scan technique) ${ }^{[14]}$. Standardization during imaging was achieved through adjusting the patient positioning laser beams as follows: The seat height was adjusted to position the region of interest (ROI) vertically within the field of view (FOV). The upper laser beam indicated the top of the FOV and the lower laser beam indicated the bottom of the FOV. The sagittal laser beam (vertical front beam) was positioned in the center of the FOV from sagittal direction so that it is in the center of the ROI. The lateral laser beam (vertical side beam) was positioned in the center of the FOV in the lateral direction so that it is in the center of the ROI. The patient was instructed not to move during the duration of exposure. Exposure was performed at $15 \mathrm{~mA}, 85 \mathrm{KV}$ and at a field of view $7.5 \mathrm{~cm} \times 14.5$ $\mathrm{cm} \times 14.5 \mathrm{~cm}$ for radiographing the mandible Image acquisition of the data was automatically performed by the computer then transferred via Ethernet connection to the workstation for reconstruction by special software *("Ondemand3d version 1.0.9, Cybermed, Korea). (Fig.2) according to type of surgical guide used for implant 


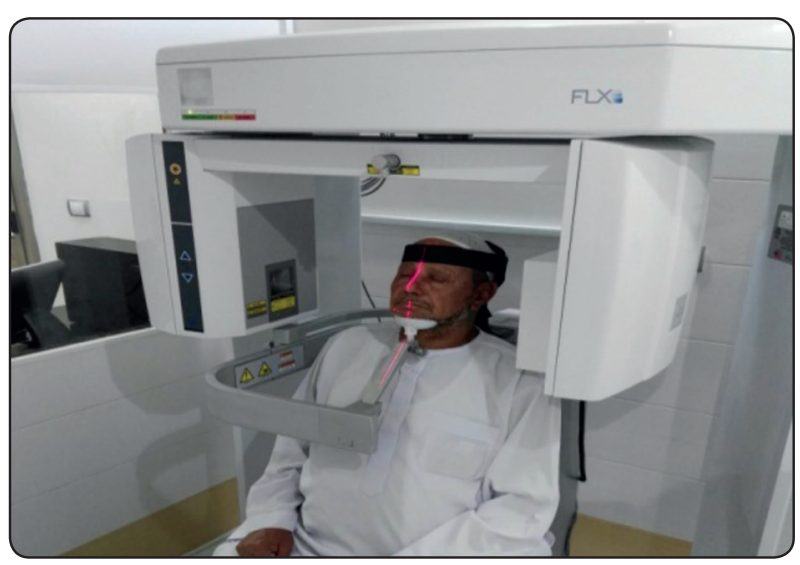

Fig. (2) Patient was radiographed by CBCT

Image reconstruction was performed including axial, sagittal, coronal and 3D views. On the axial cut, the coronal orientation line was adjusted to be perpendicular on the long axis of the ridge in buccolingual direction, (called corrected coronal cut or cross-sectional cut). The sagittal orientation line was adjusted on the axial view to pass through the long axis of the mesio-distal dimension of the ridge (called corrected sagittal cut)Linear measurements were recorded on the cross-sectional view including bone height and bucco-lingual bone width (Fig. 3).

Virtual implant simulation with a suitable sized implant was selected such that the implant is $2 \mathrm{~mm}$ away from the inferior alveolar canal, surrounded by at least $1 \mathrm{~mm}$ of bone bucco-lingually. The chosen virtual implant was placed with an appropriate angulation in all 3 dimensions, followed by fine adjustment in the virtual implant position. The virtual implant within the bone images and the radiographic template image were fused together and saved as a new DICOM file.

The radiographic treatment plan was modified by selecting the proper sleeves (In 2Guide universal kit, Cybermed, Korea.Dntium) in the position and direction of virtual implant place and adding the position of the anchor pins according to the availability of bone in each case. The fused image of radiographic templates after modification was separated from the past DICOM file and saved on the software as STL (solid to layer) file ${ }^{[15]}$.

The STL file was imported to the $3 \mathrm{~d}$ printer and printed by photo sensitive polymerized material (Envision Tec's Clear Guide Perfactory Material,Envesiontec Co.,Brüsseler Strabe, Gladbeck, Germany.). After preparation of surgical guide it was polished and cleaned with isopropanol to remove uncured polymer. The cleaned polymers were cured with Otoflash(Otoflash Post Curing System, Envesiontec Co., Brüsseler Strabe, Gladbeck, Germany) curing system to complete curing of surgical guide then the metal sleeves of implant drill and fixation pins were fixed in its places by the friction fit according to planning.(Fig1.B)

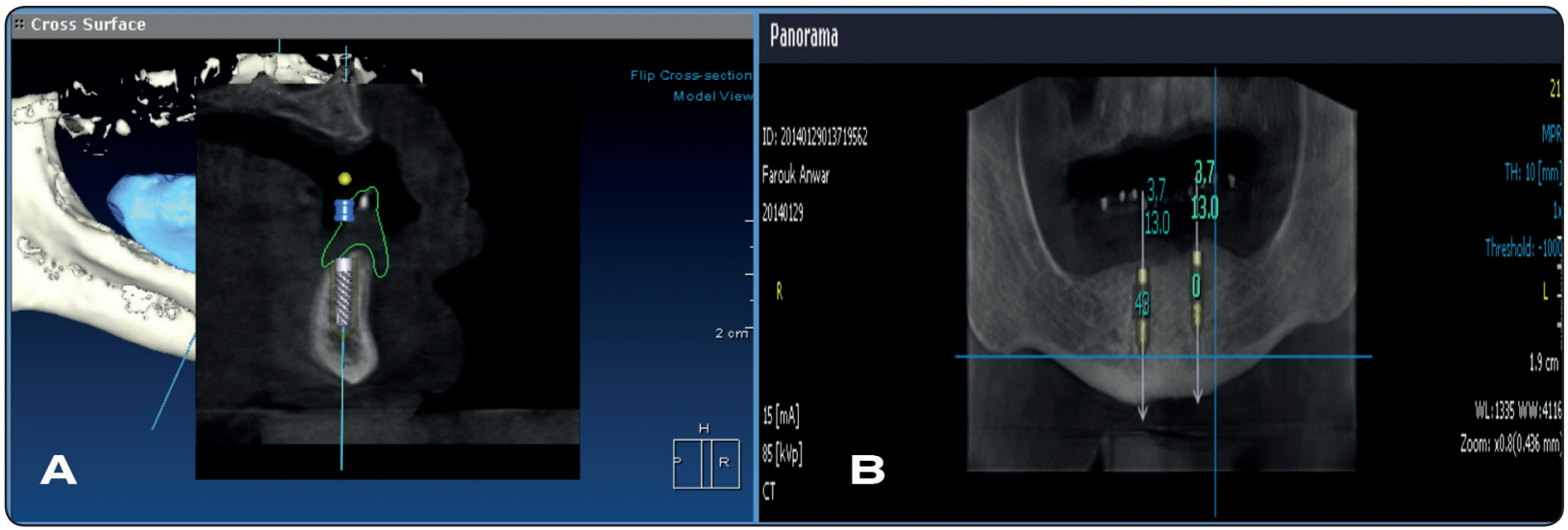

Fig. (3) Virtual implants placement 
For every patient, two implants with the same length, diameter and type of the virtual preplanned implant was selected according to the previous radiographic examination. Surgical guide and the implant surgical kit (Dentium Implant System Korea) were prepared and sterilized.

\section{The patients divided into two groups.}

\section{Group I: Bony supported surgical guide:}

A crestal incision was made and a full tickness mucoperiosteal flap was then reflected in the interforaminal region from premolar area on one side to another side using a mucoperiosteal elevator, then The $3 \mathrm{D}$ printed surgical guide was inserted in the patient mouth on the bone and fixed in its place by the planned anchor pins followed by insertion of the pilot drill then the intermediate and final drill at a low speed with high torque together with saline as a coolant through the surgical guide. Drilling of the osteotomy site was performed with surgical drills in a sequential manner following the manufacturer's directions. Insertion of the final drill was then performed by the depth control surgical kit and the implant site was ready for implant insertion.

Implant of the appropriate length and width (according to pre-surgical planning) was installed in the osteotomy site with a torque wrench and the cover screw was placed. The flap was repositioned properly and sutured using 000 black silk in an interrupted manner. (Fig.4A, B, C, D)

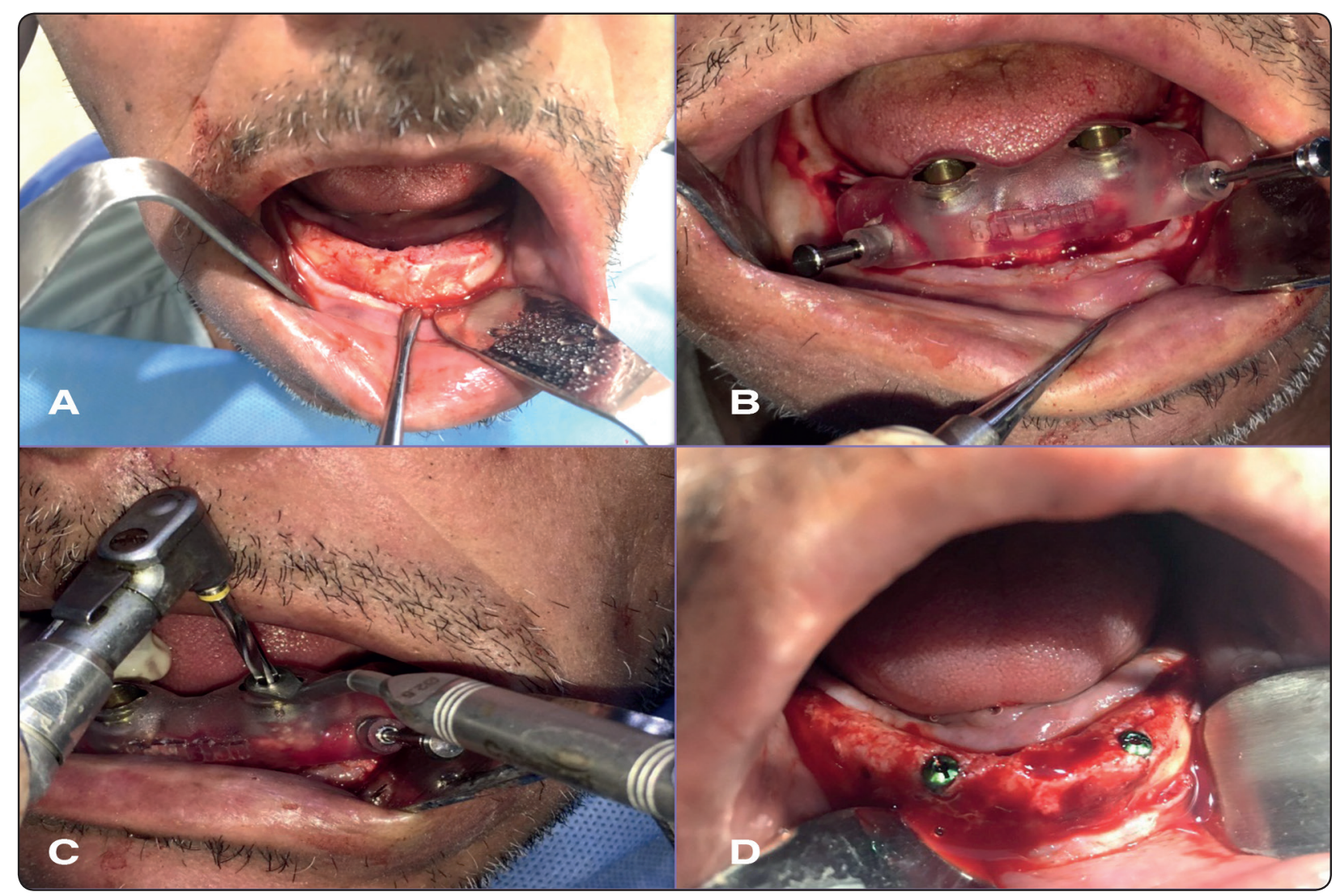

Fig. (4) (A) The bone-supported guides required an open flap reflection. (B) Bone supported surgical guide securely placed onto the bone in a close fit without any movement or rocking. $(\mathbf{C}, \mathbf{D})$ The template allows for precise osteotomy preparation and insertion of two implant in the interforaminal region of the mandible. 


\section{Group II: Mucosal supported surgical guide:}

By the flapless implant insertion technique, the 3D printed surgical guide was inserted in the patient mouth over the mucosa, fixed in its place by the planned anchor pins followed by insertion of the pilot drill then the intermediate and final drill through the surgical guide by the depth control surgical kit and with good saline irrigation to overcome over heating during drilling inside the surgical guide. (Fig.5A,B)

The patients were not allowed to wear their complete denture for 2 weeks after surgery. The denture was then relieved in the implant area and a soft liner* (Acrostone Relining Materials, Egypt ) was applied during denture wearing through-out the healing period.

\section{Methods of evaluation}

\section{Measuring the accuracy of the surgical guide}

On the postoperative image after implant insertion, the virtual implant plane was imported and superimposed over the image of the real implant then the file saved. The difference between the real implant and virtual implant was analyzed by computer softwareto record linear and angular deviations ${ }^{7}$.

\section{1- Recorded linear deviation}

The linear deviation was recorded for each implant. The central axis of the placed implant and the virtual implant was determined. And the linear distance between both was measured. The central axis at the coronal and apex of the implants was measured in $\mathrm{mm}$. and the linear values were recorded and compared in two groups included:

\section{A-Coronal linear deviation:}

The coronal linear deviations for both groups were measured at three axes. $\mathrm{X}$ axis (bucco- lingual), $\mathrm{Y}$ axis (mesio- distal) and $\mathrm{Z}$ axis (vertical)

\section{B-Apical linear deviations:}

The apical linear deviations in two groups were measured at $\mathrm{X}$ axis (bucco- lingual), $\mathrm{Y}$ axis (mesiodistal) and $\mathrm{Z}$ axis (vertical)

\section{2- Angular deviation}

The central axis of the placed implant and the virtual implant was determined and the angular deviation between the central axes of the implants was measured in degree. The angular values were recorded and compared in two groups.

\section{Statistical analysis}

Data was evaluated using SPSS software (Statistical Package for Social Science, IBM Corporation, NY, USA). Data were collected, tabulated and analyzed using Student t- test. The threshold for significance was set at $\mathrm{P} \leq .05$.

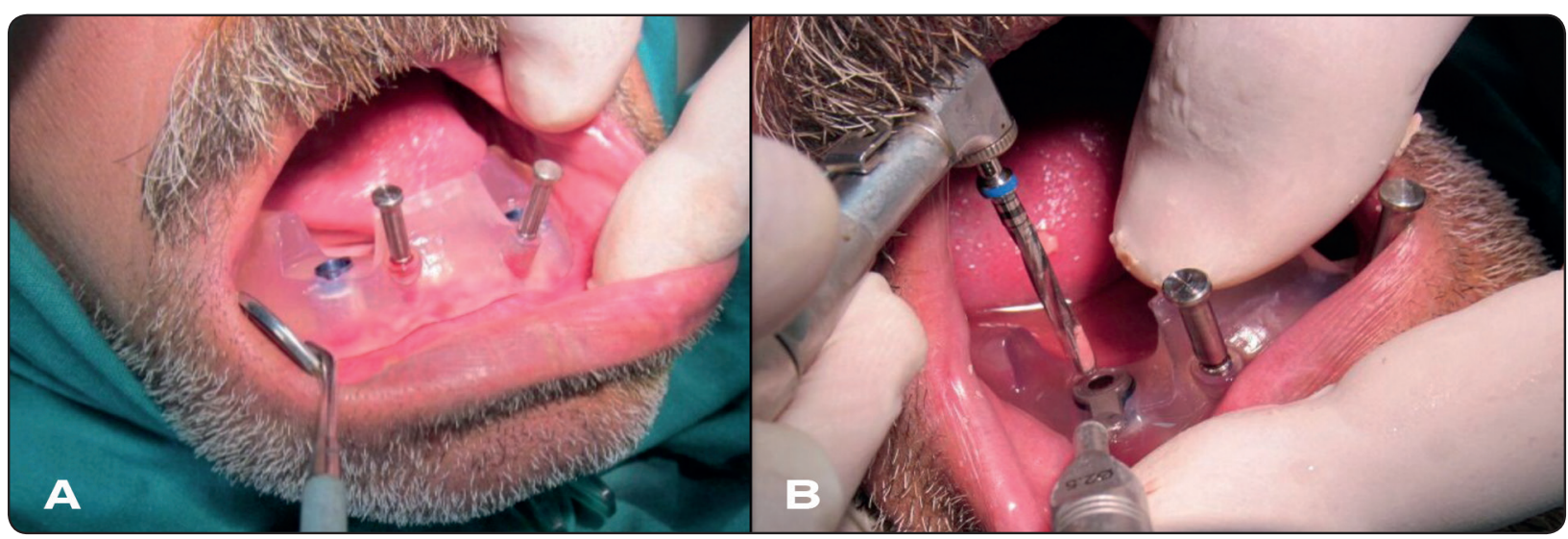

Fig. (5) (A, B) Mucosa-supported surgical guide allows the guided implant site preparation and insertion without flap elevation. 


\section{RESULTS}

\section{1- Recorded linear values}

\section{A-Coronal linear deviation:}

The coronal linear deviations for the two groups were divided into three axes. $\mathrm{X}$ axis (bucco- lingual), $\mathrm{Y}$ axis (mesio- distal) and $\mathrm{Z}$ axis (vertical).

\section{Coronal X-axis}

Mean and standard deviation values for group I (bony supported) were $(0.89 \pm 0.6412)$. and for group II (mucosa supported) were $(0.819 \pm 0.5556)$ There was no statistical significant difference between group I and group II $(P>0.05)$.

\section{Coronal Y- axis}

Mean and standard deviation values for group I (bony supported) were $(1.053 \pm 0.4765)$ and for group II (mucosa supported) were $(1.139 \pm 0.5077)$ There were no statistical significant differences recorded at the coronal Y-axis between the groups.

\section{Coronal Z - axis}

Mean and standard deviation values for group I(bony supported) were $(1.057 \pm 1.1082)$ and for group II (mucosa supported) were $(1.114 \pm 0.974)$. There was no significant difference between group I and group II $(\mathrm{P}>0.05)$.

\section{B-Apical linear deviations:}

The apical linear deviations in both groups were divided into $\mathrm{X}$-axis (bucco- lingual), Y- axis (mesio- distal) and Z- axis (vertical).

\section{Apical X-axis}

The mean and standard deviation values for group I (bony supported) were $(1.102 \pm 0.8798)$ and for group II (mucosally supported) were (1.311 $\pm 0.8327)$. There was no significant difference between group I and group II $(\mathrm{P}>0.05)$.

\section{Apical Y- axis}

The mean and standard deviation values for group I (bony supported) were $(1.251 \pm 0.7851)$. and for group II (mucosally supported) were (1.158 $\pm 0.5988)$.There was no significant difference between group I and group II $(\mathrm{P}>0.05)$.

\section{Apical Z - axis}

The mean and standard deviation values for group I (bony supported) were $(1.024 \pm 1.1337)$ and for group II (mucosally supported) were (1.018 $\pm 0.5471)$.There was no significant difference between group I and group II ( $\mathrm{P}>0.05)$.

\section{2- Angular deviation}

The mean and standard deviation values for group I (bony supported) were $(5.511 \pm 1.966)$. and for group II (mucosally supported) were (5.518 1.0901). There was no significant difference between group I and group II (P>0.05). Fig 6, Table 1 


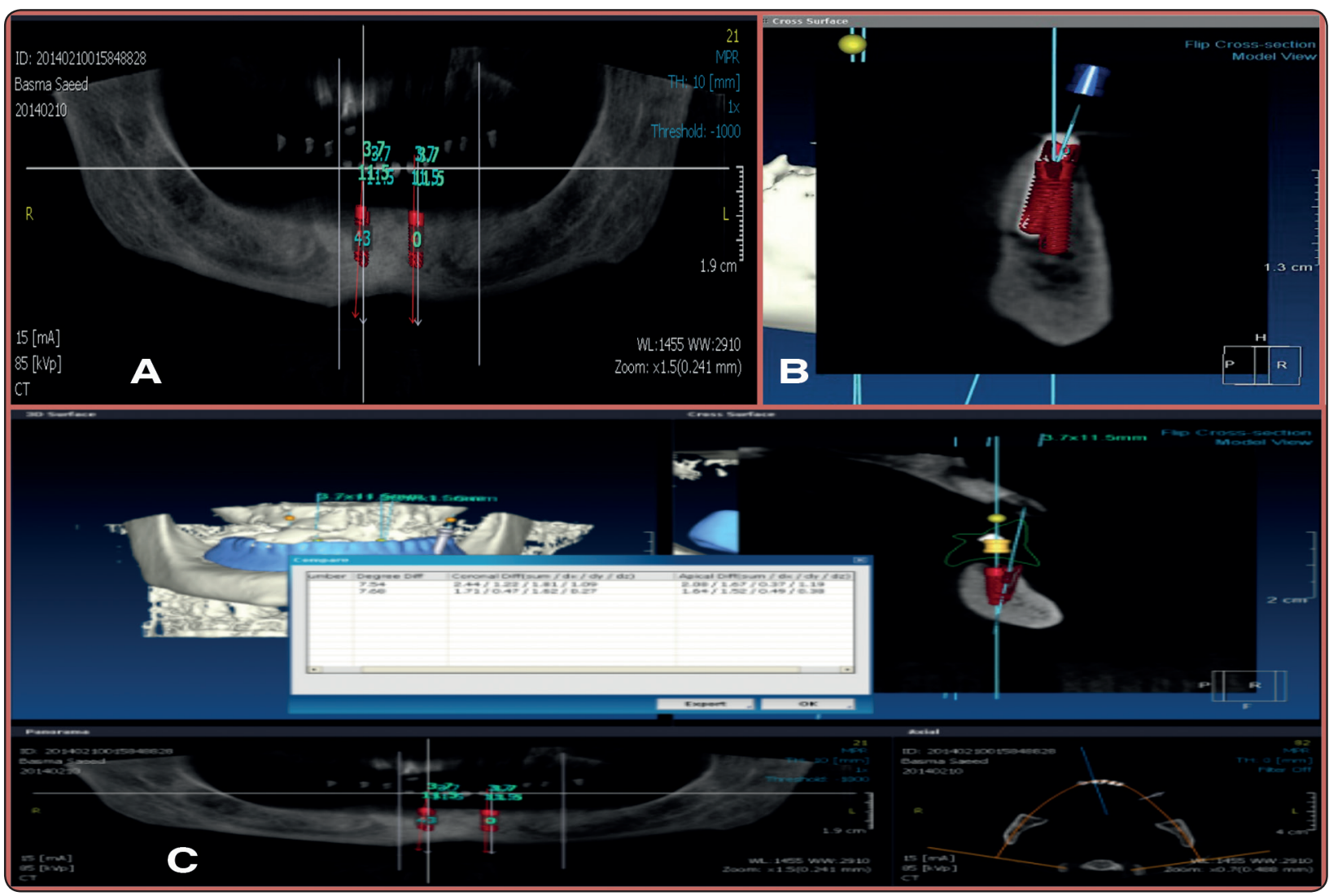

Fig. (6) Three-dimensional evaluationof differences between real and virtual implants

TABLE (1) Differences by mm between mucosally and Bony supported surgical guides

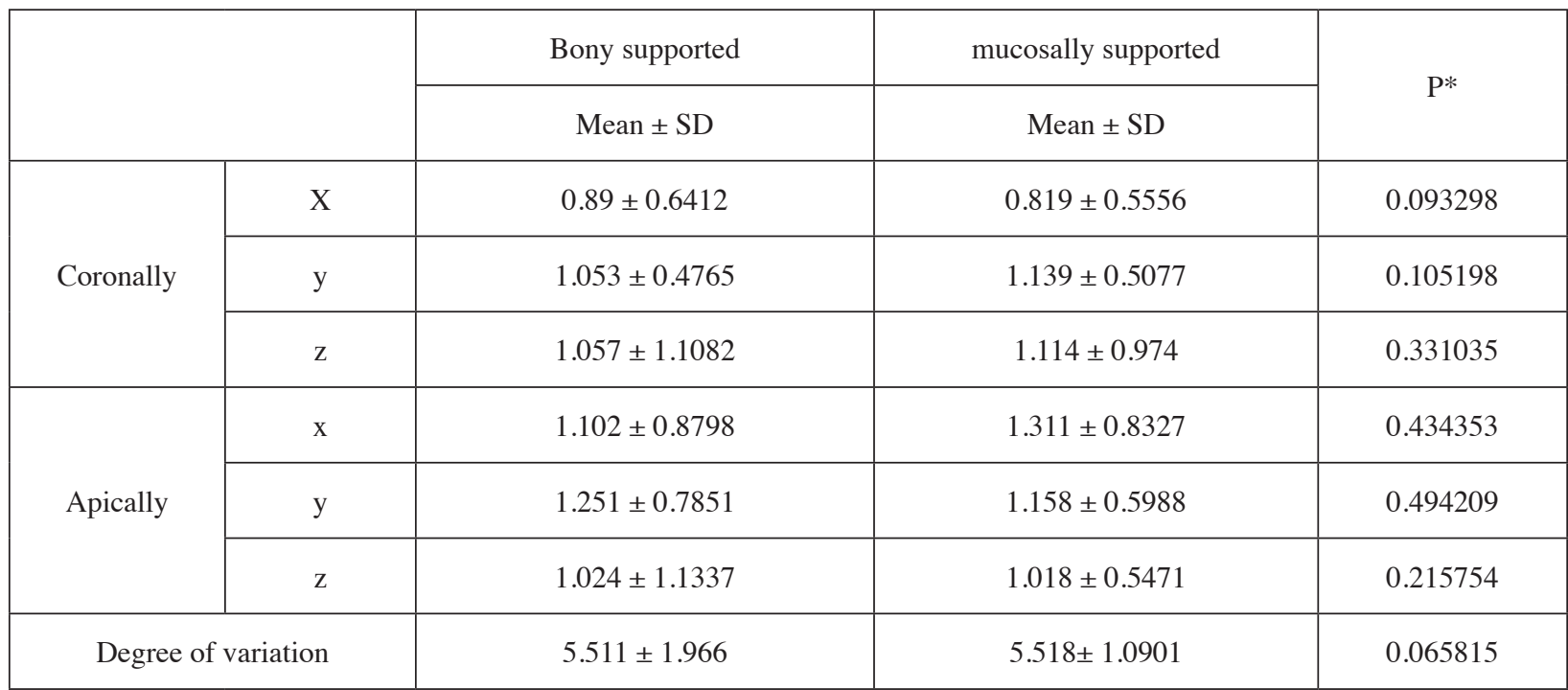

$(p>0.05)$ 


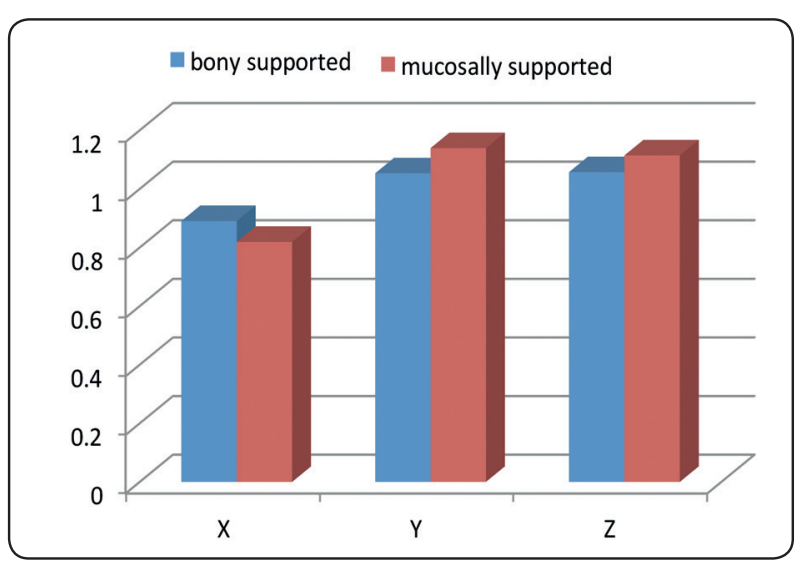

Fig. (7) Bar graph showing differences by mm between mucosally and Bony supportedsurgical guides. Coronally in axis $\mathrm{x}, \mathrm{y}, \mathrm{z}$

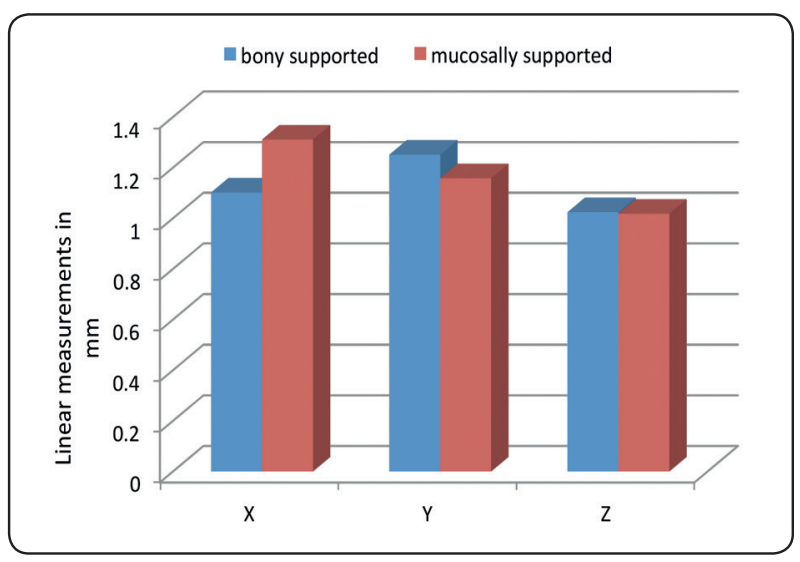

Fig. (8) Bar graph showing differences by mm between mucosally and bony supported surgical guides. Apically in axis $x, y, z$

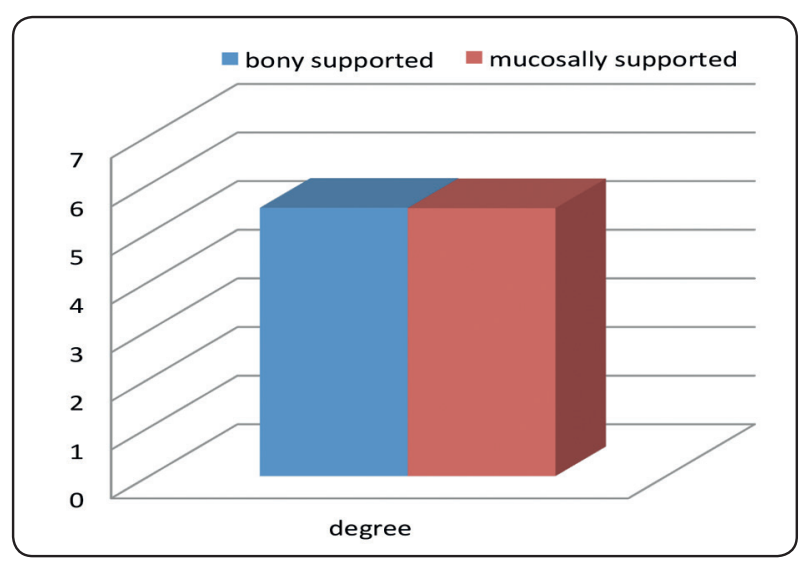

Fig. (9) Bar graph showing differences by degree between mucosally and bony supported surgical guides in the angle variations

\section{DISCUSSION}

Anatomical limitation and better prosthetics requests more precision in surgical positioning of dental implants. During oral implant placement, the drill (position, depth and angulation) must be guided according to the final form of the prosthetics. Ideal placement facilitates the establishment of favorable forces on the implants and the prosthetic component ${ }^{[16,17]}$. A possible explanation for the poor outcome of implants placed by inexperienced surgeons is that with less experience the frequency of problems such as excessive heat during drilling, non-stabilization of the implant, lack of adequate planning may increase ${ }^{[18,19]}$.

CBCT images offered a significantly clearer perception of both the spatial resolution and delineation of the inferior alveolar nerve canal when compared to conventional 2D panoramic images. CBCT images were found to be superior to panoramic images ${ }^{[20-22]}$. A computer system with excellent support would be beneficial for both the patient and the operator. The use of medical imaging and software planning has led to considerable improvement in treatment planning ${ }^{[23]}$.

In the current study, the surgical guide was fabricated by rapid prototyping from CBCT data. Rapid prototyping technologies can construct physical models from computer aided design via 3-dimensional (3D) printers. It is possible to fabricate surgical guides that can place the implants in the same places and same directions as those in the planned computer ${ }^{[24,25]}$. CAD/CAM surgical guided templates can also facilitate optimal implant placement and can simplify the surgical procedure. The use of surgical guided template can minimize the micro-movements which might occur during implant placement.

A surgical guide was used in this study to allow transferring the optimal virtual implant planning on the computer to the exact same actual position in the patient's mouth. This was performed in all three 
dimensions; bucco-lingual, mesio-distal and apicocoronal directions to enable optimization of implant position, angle, diameter and length ${ }^{[26,27]}$

The evaluation method carried out in this study was measurement of deviation in the post-operative implant position from the preoperative virtual implant planning concerning the coronal and apical linear deviation and the inter-implant angle. This was done by superimposition of the CBCT images of pre-operative virtual planning with the postoperative actual implant placed in the patient's mouth $^{[28,29]}$. CBCT has been shown to be accurate to within 0.1 to $0.2 \mathrm{~mm}$ for measures over long distances between anatomic landmarks ${ }^{[30,31]}$ however, others found that CBCT overestimated measurements by $0.2 \mathrm{~mm}$. This overestimation increased to $2.2 \mathrm{~mm}$ for all intra-bony measurements ${ }^{[32]}$. The virtual implant position planned on the pre-operative CBCT was considered as the gold standard i.e. the best desired implant position after surgery was zero $\mathrm{mm}$ deviation \& zero degrees angle. Linear deviation more than $2 \mathrm{~mm}$ was considered clinically significant, where an angle more than 15 degrees was considered significant (which is the angle above an angled abutment would be required ${ }^{[33]}$.

The results of this study showed that stereolithographic surgical guides may be reliable in implant placement and that there was no statistically significant difference between the bone supported and the mucosa supported surgical guide when comparing angular deviation. These results were in agree with Lee et $\mathrm{a}^{34}$ who concluded that, the template supporting type did not largely affect the accuracy as the template-guided implant surgery can be performed stably regardless of supporting type and arch but, the control of errors at the coronal level is needed to decrease the error at the apical center for the protection of anatomical structures in the surgical procedure.

The deviations or the inaccuracy in implant positioning could be generated from the cumulative errors throughout the "computer-aided implant, as imaging, software planning and guide manufacturing as simulation software production, precision of the stereo-lithographic machine, production and quality control, rigidity and physical properties of the material used, placement method and precision of the guide cylinders, metal tubes, and verification of the guide ${ }^{35}$. As reported with Valente et al ${ }^{33}$, proper guide positioning in the mouth, rotational allowance of drills in tubes, shape and sharpness of the drills and mouth opening, all of these factors can reduce deviations.

When comparing bone supported (BSG) versus mucosa supported surgical guide(MSG), it has been demonstrated that a prolonged oral surgical intervention of BSG may increase post-operative discomfort and morbidity ${ }^{[36]}$. According to the claims of guide manufacturers, the mean surgery duration of the BSG group was only 8 min shorter than the MSG. However, the average time in the MSG group was $23 \mathrm{~min}$, which was significantly shorter than the BSG. Furthermore, the absence of fixation in the BSG caused occasional movement of the guide that resulted in a pause during surgery for re-positioning of the guide ${ }^{[37]}$. Flapless group may help to reduce pain and analgesic consumption in the post-implant surgery period, especially in totally edentulous jaws considered for a fixed restoration. Another noteworthy finding that may be related to the use of non-invasive surgery was the statistically significant reduction in hemorrhaging in the Flapless group on the day of the surgery, compared with the BSG. On the other hand, the width of keratinized mucosa that was preserved in the BSG groups was removed by the mucotome of the mucosa-supported guides and this may compromise peri-implant health conditions in the long term ${ }^{[38]}$.

The use of mucosa-supported SLA guides for flapless placement of implants reduced the surgery duration, pain intensity, analgesic consumption and most other complications typical in the post- 
implant surgery period. Nevertheless, the procedure is technically demanding and suitable only for selected patients. ${ }^{[39,40]}$

Increasingly, studies confirm the high predictability of 3D planning software in regards to their ability to offer absolute precision between what is planned and what is accomplished surgically. The use of surgical computer-guided planning changes the surgeon's approach: whereas the use of conventional guides permitted a certain degree of offset from what was planned, the use of computer guides allows implants to be inserted in a far more precise way. It is obvious that careful planning is the key factor in order to avoid implant misplacement ${ }^{[10]}$.

In contrast, other studies reported that there are some disadvantages for computer guiding methods must be emphasized which are the familiarity with the whole system and the total cost of required tools, including software program, surgical templates, and so on, are most important and must be carefully reviewed with the patient. Added to, the degree of accuracy of the technique depends in many aspects to the degree of precision of image acquisition technique, which must be carefully controlled by the radiologist. It must be pointed out that the stereolithographic templates are made of some type of resin. It is noteworthy that these types of materials are nevertheless water absorbable and heat sensitive and therefore may undergo some deformation during delivery time ${ }^{41}$.

\section{CONCLUSIONS:}

Using template-guided surgery enables the clinician to optimize implant position, angle, diameter and length by dictating the drilling position and angulation. Cone beam CT has accurate measurements in distances between two implants as clinical measurements. The bony supported surgical guide as well as the mucosa supported surgical guide has the same accuracy in implant positioning.

\section{REFERENCES}

1. Akça K, Iplikçioğlu H, Cehreli MC. A surgical guide for accurate mesiodistal paralleling of implants in posterior edentulous mandible.J Prosthet Dent. 2002;87:233-5.

2. Gahleitner A, Watzek G, Imhof H. Dental CT: Imaging technique, anatomy, and pathologic conditions of the jaws. EurRadiol. 2003;13:366-76.

3. Pramono C. Surgical technique for achieving implant parallelism and measurement of the discrepancy in panoramic radiograph. J Oral Maxillofac Surg. 2006;64:799-803.

4. Lal K, White GS, Morea DN, Wright RF. Use of stereolithographic templates for surgical and prosthodontic implant planning and placement. Part I. The concept.J Prosthodont. 2006; 15:51-58.

5. The glossary of prosthodontic terms. J Prosthet Dent. 2005; 94:10-92.

6. Geng W, Liu C, Yucheng Su, Jun Li, Zhou Y .Accuracy of different types of computer-aided design/computer-aided manufacturing surgical guides for dental implant placement. Int J ClinExp Med. 2015; 8: 8442-49

7. Turbush SK, Turkyilmaz I. Accuracy of three different types of stereolithographic surgical guide in implant placement: An in vitro study. J Prosthet Dent. 2012;108:81

8. Orentlicher G, Abboud M. Guided surgery for implant therapy. Dent Clin North Am. 2011;55:715-44.

9. Nickenig HJ, Eitner S. Reliability of implant placement after virtual planning of implant positions using cone beam CT data and surgical (guide) templates. J Craniomaxillofac Surg. 2007;35:207-11.

10. Ozan O, Turkyilmaz I, Ersoy AE, McGlumphy EA, Rosenstiel SF. Clinical Accuracy of 3 Different Types of Computed Tomography-Derived Stereolithographic Surgical Guides in Implant Placement. J Oral Maxillofac Surg. 2009;67:394-401

11. Veyre-Goulet S, Fortin T, Thierry A. Accuracy of linear measurement provided by cone beam computed tomography to assess bone quantity in the posterior maxilla: A human cadaver study.Clin Implant Dent Relat Res. 2008;10:226-30.

12. Mora MA, Chenin DL, Arce RM. Software tools and surgical guides in dental-implant-guided surgery. Dent Clin North Am. 2014;58:597-26. 
13. Tahmaseb A, Wismeije D, Coucke W, Derksen W. Computer Technology Applications in Surgical Implant Dentistry: A Systematic Review.Int J Oral Maxillofac Implants 2014;29:25-42.

14. Sanna AM, Molly L, van Steenberghe D. Immediately loaded CADCAM manufactured fixed complete dentures using flapless implant placement procedures: a cohort study of consecutive patients. J Prosthet Dent. 2007;97:331-9.

15. Lehmann TM, Troeltsch E, Spitzer K. Image processing and enhancement provided by commercial dental software programs.DentomaxillofacRadiol. 2002;31:264-72.

16. Orentlicher G, Abboud M. Guided surgery for implant therapy. Oral MaxillofacSurgClin North Am 2011;23:239-56

17. El Askary, Abd El Salam. Reconstructive Aesthetic Implant Surgery. Iowa: Blackwell Munksgaard; 2003. p. 33-4.

18. Kohavi, D., Azran, G., Shapira, L. \& Casap, N. Retrospective clinical review of dental implants placed in a university training program. The Journal of Oral Implantology 2004,30: 23-9

19. Melo M D, Shafie H. , Obeid G. Implant survival rates for oral and maxillofacial surgery residents: a retrospective clinical review with analysis of resident level of training on implant survival. Journal of Oral and Maxillofacial Surgery.American Association of Oral and Maxillofacial Surgeons 2006,64: 1185-88

20. Angelopoulos C, Thomas SL, Thomas S, Hechler S, Hechler S, Parissis N, et al. Comparison between digital panoramic radiography and cone-beam computed tomography for the identification of the mandibular canal as part of presurgical dental implant assessment. J Oral Maxillofac Surg. 2008;66:2130-5

21. Pawelzik J, Cohnen M, Willers R, Becker J. A comparison of conventional panoramic radiographs with volumetric computed tomography images in the preoperative assessment of impacted mandibular third molars. J oral Maxillofac Surg. 2002;9:979-84.

22. Peck JL, Sameshima GT, Miller A, Worth P, Hatcher DC. Mesiodistal root angulation using panoramic and cone beam CT. Angle Orthod. 2007;77:206-13.

23. Alqerban A, Jacobs R, Souza PC, Willems G. In-vitro comparison of 2 cone-beam computed tomography systems and panoramic imaging for detecting simulated canine impaction-induced external root resorption in maxillary lateral incisors. Am J Orthod DentofacOrthop. 2009;136:1-11.
24. Umapathy T, Jayam C, Anila BS, AshwiniCP.Overview of surgical guides for implant therapy.J Dent Implant 2015;5:48-52

25. Sammartino G, Della Valle A, Marenzi G, Gerbino S, Martorelli M, di Lauro AE, et al. Stereolithography in oral implantology: a comparison of surgical guides. Implant Dent. 2004;13:133-9.

26. Cohen A, Laviv A, Berman P, Nashef R, Abu-Tair J. Mandibular reconstruction using stereolithographic 3-dimensional printing modeling technology. Oral Surgery, Oral Med Oral Pathol Oral RadiolEndodontology. 2009;108:661-6.

27. Grefrenstein G, Cavallaro J. The relationship between biologic concepts and fabrication of surgical guides for dental implant placement.CompendContinEduc Dent. 2007;28:196-203.

28. Viegas VN, Dutra V, Pagnoncelli RM, de Oliveira MG. Transference of virtual planning and planning over biomedical prototypes for dental implant placement using guided surgery. Clin Oral Implants Res. 2010;21:290-5.

29. Soares MM, Harari ND, Cardoso ES, Manso MC, Conz MB, Vidigal GM. An in vitro model to evaluate the accuracy of guided surgery systems. Int J Oral Maxillofac Implants. 2012;27:824-31

30. Molen AD. Considerations in the use of cone-beam computed tomography for buccal bone measurements. Am J OrthodDentofacOrthop. 2010;137:30-6.

31. Baumgaertel S, Palomo JM, Palomo L, Hans MG. Reliability and accuracy of cone-beam computed tomography dental measurements. Am J OrthodDentofacOrthop. 2009;136:19-25.

32. Stratemann SA, Huang JC, Maki K, Miller AJ, Hatcher DC. Comparison of cone beam computed tomography imaging with physical measures. DentomaxillofacRadiol. 2008;37:80-93

33. Valente F, Schiroli G, Sbrenna A. Accuracy of computeraided oral implant surgery: a clinical and radiographic study. Int J Oral Maxillofac Implants. 2009;24:234-42.

34. Lee JH, Park JM, Kim SM, Kim MJ, Lee JH, Kim MJ.. An assessment of template-guided implant surgery in terms of accuracy and related factors.J Adv Prosthodont. $2013 ; ; 5: 440-7$.

35. van Steenberghe D, Naert I, Andersson M, Brajnovic I,Van Cleynenbreugel J, Suetens P. A custom templateand 
definitive prosthesis allowing immediate implant loading in the maxilla: A clinical report. Int $\mathbf{J}$ OralMaxillofac Implants 2002;17:663-0

36. Sato, F.R., Asprino, L., de Araujo, D.E. \& de Moraes, M. Short-term outcome of postoperative patient recovery perception after surgical removal of third molars. The International Journal of Oral and Maxillofacial Surgery 2009, 67: 1083-91

37. Komiyama, A., Klinge, B. \&Hultin, M. Treatment outcome of immediately loaded implants installed in edentulous jaws following computer-assisted virtual treatment planning and flapless surgery. Clin Oral Implants Res. $2008 ; 19: 677-85$.

38. Schrott, A.R., Jimenez, M., Hwang, J.W., Fiorellini, J. \& Weber, H.PFive-year evaluation of the influence of keratinized mucosa on peri-implant soft-tissue health and stability around implants supporting full-arch mandibular fixed prostheses. Clinical Oral Implants Research . 2009,20: 1170-77.

39. Campelo, L.D. \&Camara, J.R. Flapless implant surgery: a 10-year clinical retrospective analysis. The International Journal of Oral \& Maxillofacial Implants 2002;17: 271-76

40. Kim, J I, Choi BH, Li J, Xuan F, Jeong S M. Blood vessels of the peri-implant mucosa: a comparison between flap and flapless procedures. Oral Surgery, Oral Medicine, Oral Pathology, Oral Radiology, and Endodontics 2009;107: 508-12.

41. Nikzad Sand Azari A. A Novel Stereolithographic Surgical Guide Template for Planning Treatment Involving a Mandibular Dental Implant. J Oral Maxillofac Surg.2008; 66:1446-54. 